\title{
TUMOR DE CÉLULAS GIGANTES ÓSSEO: ASPECTOS CLÍNICOS E RADIOGRÁFICOS DE 115 CASOS*
}

\author{
Julian Catalan ${ }^{1}$, Alexandre Calábria da Fonte ${ }^{1}$, Joel Rodrigo Beal Lusa ${ }^{1}$, Alex Dias de Oliveira ${ }^{1}$, \\ Elisa Soares de Melo ${ }^{1}$, Reinaldo Ottero Justino Júnior ${ }^{1}$, Tjioe Tjia Min ${ }^{1}$, Ana Carolina Mori Lima ${ }^{1}$, \\ Carlos Marcelo Gonçalves ${ }^{2}$
}

\begin{abstract}
Resumo OBJETIVO: Analisar os aspectos clínicos e radiográficos em pacientes com diagnóstico de tumor de células gigantes ósseo, confirmado por histopatologia. MATERIAIS E MÉTODOS: Os dados clínicos e radiológicos (quando disponíveis) de 115 pacientes com diagnóstico de tumor de células gigantes ósseo foram analisados no presente estudo. RESULTADOS: Dos casos avaliados, $57,4 \%$ (66) eram do sexo feminino e $80 \%$ (92) eram da raça branca. A média de idade dos pacientes foi de 30 anos e a topografia mais freqüente das lesões foi a metáfise distal do fêmur, em $22,6 \%(26)$ dos casos. 0 aspecto radiográfico mais comum foi o de lesão puramente lítica, em 63,7\% (51) dos casos. CONCLUSÃO: 0 tumor de células gigantes é uma neoplasia óssea relativamente comum, com predomínio em indivíduos da raça branca e com aspecto radiológico bem definido.

Unitermos: Radiologia convencional; Tumor de células gigantes; Neoplasias ósseas.
\end{abstract}

Abstract Giant cell tumor of bone: clinical and radiographic aspects of 115 cases.

OBJECTIVE: To review clinical and radiographic findings in patients with histologically confirmed giant cell tumor of bone. MATERIALS AND METHODS: Clinical and radiological data of $\mathbf{1 1 5}$ patients with giant cell tumor of bone were analyzed. RESULTS: Of the evaluated cases, $57.4 \%(66)$ were female and $80 \%(92)$ were white. The patients were 30 years old in average and the most common site of the lesions was the distal femoral metaphysis, in $22.6 \%(26)$. The most common radiographic aspect was a purely lytic lesion, in $63.7 \%(51)$ of the cases. CONCLUSION: Giant cell tumor of bone is not an uncommon tumor, predominant in the white race, with radiological findings well established.

Keywords: Conventional radiology; Giant cell tumor of bone; Bone neoplasms.

\section{INTRODUÇÃO}

O tumor de células gigantes (TCG) é uma das neoplasias ósseas primárias mais comuns, que se apresenta na maioria das vezes como lesão benigna. A ampla maioria dos tumores acomete indivíduos da segunda à quarta década de vida, com discreto predomínio do sexo feminino. Dor e aumento de volume local são as queixas mais freqüentes. Classicamente, os estudos radiográficos convencionais demonstram lesão lítica, solitária, metaepifisária, bem delimitada, sendo os ossos da região do

* Trabalho realizado no Centro de Tratamento e Pesquisa Hospital do Câncer - A.C. Camargo, São Paulo, SP.

1. Médicos Residentes do Departamento de Imagem do Centro de Tratamento e Pesquisa Hospital do Câncer - A.C. Camargo.

2. Médico Radiologista do Departamento de Imagem do Centro de Tratamento e Pesquisa Hospital do Câncer - A.C. Camargo.

Endereço para correspondência: Dr. Alexandre Calábria da Fonte. Alameda Santos, 333, ap. 34, Cerqueira César. São Paulo, SP, 01419-000. E-mail: acfonte@ig.com.br

Recebido para publicação em 28/10/2004. Aceito, após revisão, em 18/5/2005. joelho os mais afetados. O presente estudo pretende avaliar os aspectos clínicos e radiográficos de 115 casos desta entidade diagnosticados em nossa instituição.

\section{MATERIAIS E MÉTODOS}

Foram estudados 115 casos de TCG histologicamente confirmados e diagnosticados entre 1980 e 2000 no Centro de Tratamento e Pesquisa Hospital do Câncer - A.C. Camargo, por meio de dados colhidos em prontuários e revisão do arquivo de imagens do setor de radiologia.

Não houve padronização na realização dos exames, por estes terem sido realizados na rotina do serviço ao longo dos anos, em diferentes aparelhos, sem estabelecimento de protocolo próprio.

\section{RESULTADOS}

Dos 115 pacientes, $57,4 \%$ (66) eram do sexo feminino e $42,6 \%$ (49), do sexo masculino. A raça de maior prevalência em nosso estudo foi a branca, com $80 \%$ (92), seguida da parda com $12,2 \%$ (14), negra com $6,1 \%$ (7) e amarela com $1,7 \%$ (2).

A média de idade foi de 30 anos, sendo que 34 pacientes tinham menos de 20 anos e 11 pacientes tinham mais de 50 anos, correspondendo a faixas etárias de maior raridade de surgimento desta entidade. $\mathrm{O}$ paciente mais novo tinha quatro anos de idade e o mais velho, 79 anos (Figura 1).

Clinicamente, dor e aumento de volume foram os sintomas mais importantes, em $80,8 \%$ (93) e $54 \%$ (62) dos pacientes, respectivamente. Hematúria, febre e emagrecimento foram sintomas encontrados em apenas um paciente cada, correspondendo a $0,9 \%$ da casuística.

Recidiva local foi diagnosticada após tratamento em 27,8\% (32) dos pacientes. A topografia mais comum de apresentação (Figura 2) do TCG foi a metáfise distal do fêmur (Figura 3), com 22,6\% (26) dos pacientes, seguido da tíbia proximal (Figura 4), com $20 \%$ (23), mandíbula, com $7,8 \%$ (9), e metáfise proximal do úmero e distal 


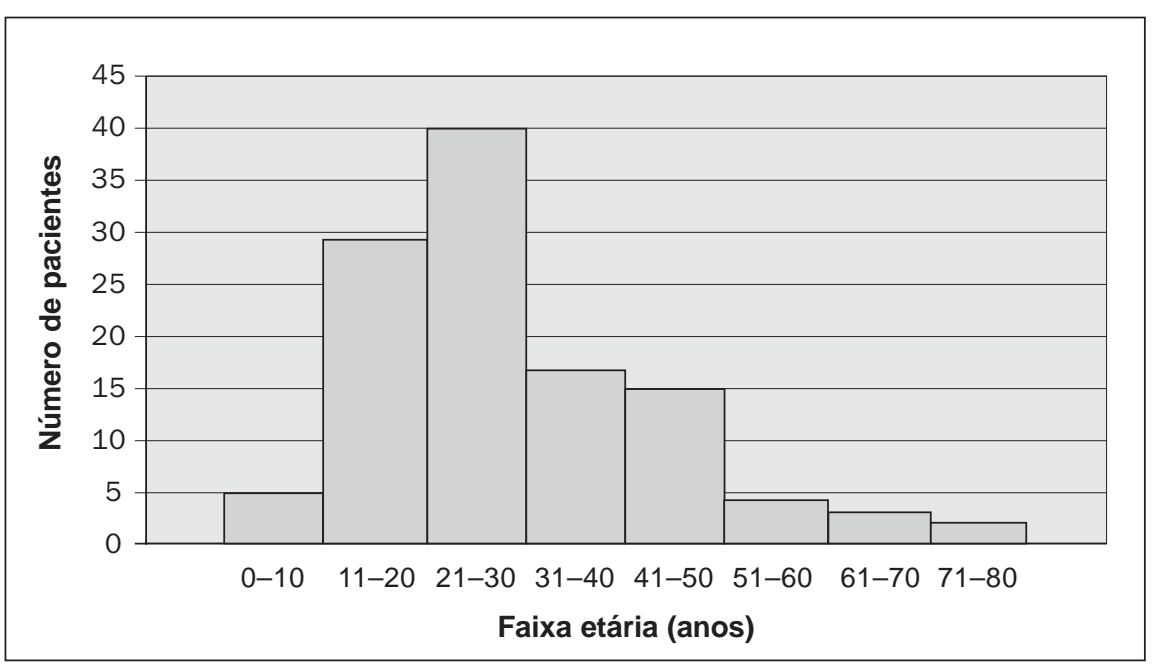

Figura 1. Gráfico demonstrando a distribuição dos pacientes com relação à faixa etária.

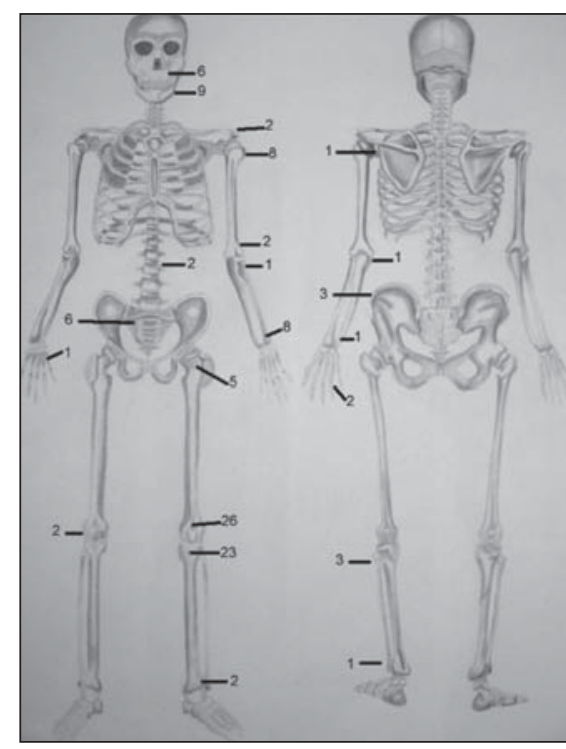

Figura 2. Desenho esquemático do esqueleto demonstrando a distribuição topográfica das lesões. Modificado de Unni( ${ }^{(3)}$.

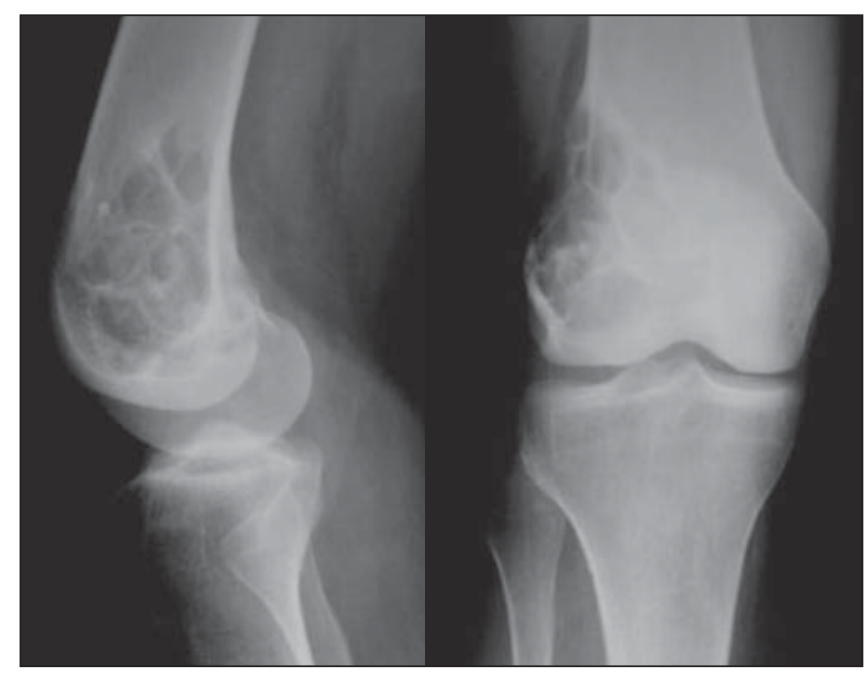

Figura 3. TCG do fêmur distal. Lesão lítica com erosão da cortical e pseudotrabeculações.

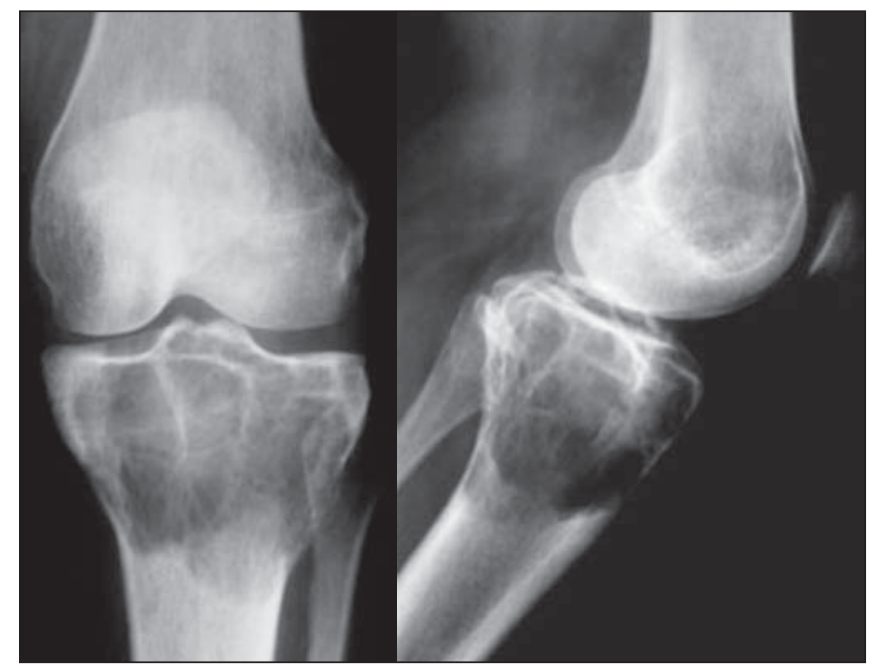

Figura 4. TCG da tíbia proximal. Lesão lítica com erosão da cortical e pseudotrabeculações. do rádio (Figura 5), cada uma com 6,9\% (8) dos pacientes.

Apenas um dos pacientes apresentou metastatização da doença e o órgão afetado foi o pulmão. Após a revisão do caso pela equipe multidisciplinar que o conduziu, estabeleceu-se que se tratava de TCG maligno da forma secundária.

Radiograficamente, o padrão mais observado foi o de lesão metafisária puramente lítica, em 63,7\% (51) (Figura 6) dos pacientes. Os outros padrões mais freqüentes foram lesão lítica com insuflação (Figura 7), em 20\% (16), e lesão lítica com septações internas (Figura 8), em 13,8\% (11) dos pacientes. Ruptura da cortical foi observada em 11,2\% (9) dos casos, aumento de partes moles em $17,5 \%$ (14), reação periosteal em $7,5 \%$ (6) e esclerose marginal em 6,25\% (5) dos casos. Não havia descrição do aspecto radiográfico pré-tratamento em 43,7\% (35) dos pacientes.

\section{DISCUSSÃO}

O TCG é uma neoplasia óssea relativamente comum, correspondendo a cerca de $5 \%$ a $10 \%$ de todos os tumores ósseos pri- mários e $15 \%$ a $25 \%$ dos tumores ósseos benignos. Caracteriza-se, microscopicamente, por grande quantidade de células gigantes em meio a estroma de células mononucleares. Não há consenso entre a maioria dos autores com relação à verdadeira histogênese dessas lesões, mas as evidências favorecem uma origem mesenquimal e que as células mononucleares seriam progenitoras das células gigantes que dão nome ao tumor ${ }^{(\mathbf{1})}$.

Existem duas variantes malignas do TCG, uma caracterizada por estroma de aspecto francamente maligno com células 


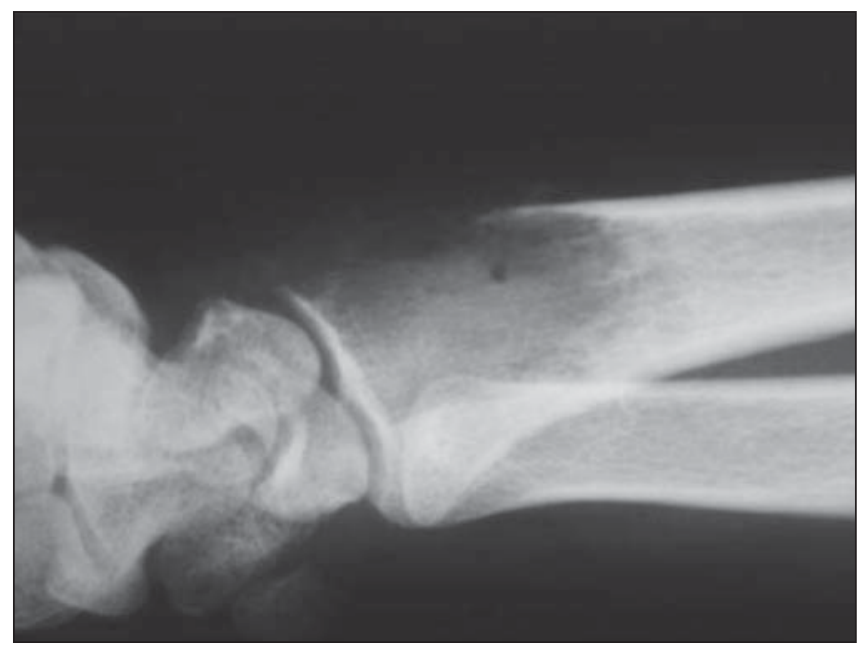

Figura 5. TCG do rádio distal. Lesão lítica com destruição da cortical.

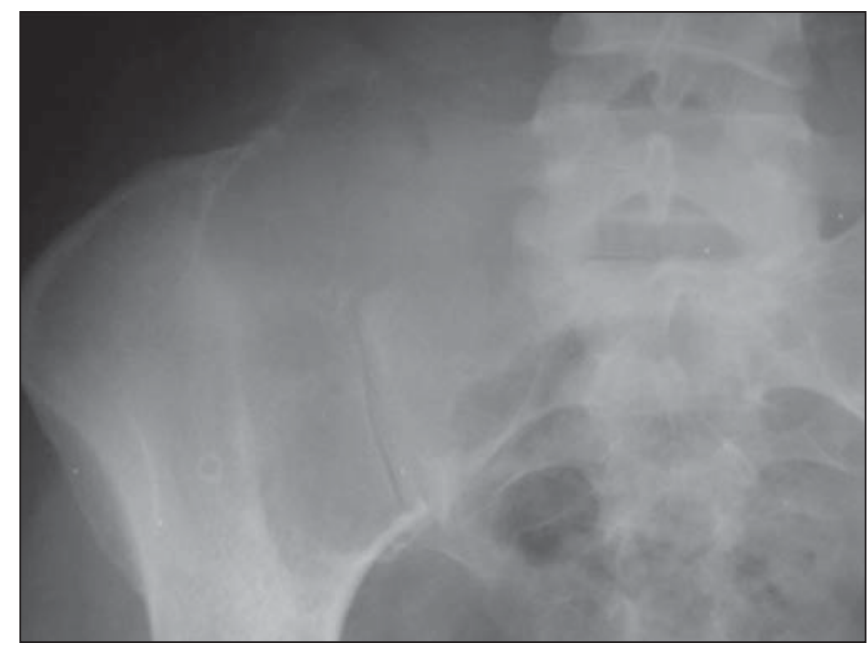

Figura 6. TCG da asa do ilíaco direito. Lesão lítico-insuflativa com aumento de partes moles adjacentes.

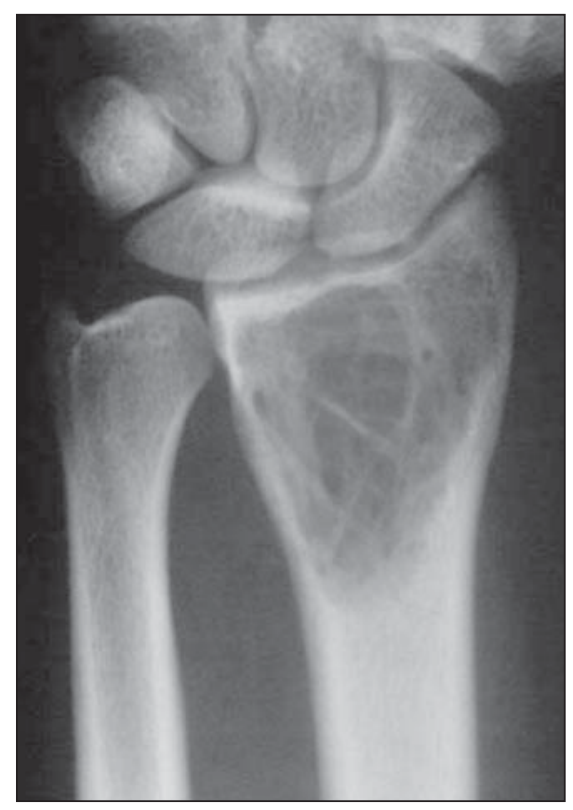

Figura 7. TCG do rádio distal, demonstrando o aspecto "em bolhas de sabão", causado pelas pseudotrabeculações ósseas.

gigantes benignas de permeio, conhecida como forma primária, e outra em que surge proliferação sarcomatosa no interior de uma lesão previamente documentada como sendo um TCG benigno ${ }^{(2)}$. Esporadicamente, mesmo um TCG com características totalmente benignas pode evoluir com metástases a distância ${ }^{(3)}$. Apenas cerca de 69 casos foram publicados na literatura indexada até o presente.

Tipicamente, surge entre os 20 e 50 anos de idade, com discreto predomínio de pacientes do sexo feminino ${ }^{(4)}$.
Dor de variável intensidade é o sintoma predominante, comumente associada a aumento de volume da região afetada.

A localização clássica dessas lesões auxilia no diagnóstico, pois se sabe que em mais de $85 \%$ das vezes se situam a até $1 \mathrm{~cm}$ do osso subarticular. $\mathrm{O}$ ponto de origem desse tumor é incerto, porém a maioria dos autores acredita que seja a face metafisária do platô epifisário ${ }^{(5)}$. Nos raros casos em que seu aparecimento precede o fechamento da fise de crescimento, a lesão tende a ter localização metafisária ${ }^{(\mathbf{6})}$. Nestes casos, deve-se ter cuidado para afastar o diagnóstico de cisto ósseo aneurismático e osteossarcoma rico em células gigantes ${ }^{(\mathbf{3})}$.

Quase metade dos casos acomete as regiões proximais do joelho, mais comumente o fêmur distal. O rádio distal e o sacro também são ossos freqüentemente envolvidos. Raramente, surgem nos pequenos ossos da mão e pés; nestes casos, parece haver maior incidência de multicentricidade tumoral ${ }^{(\mathbf{3 , 5})}$.

Radiologicamente, apresenta-se como imagem lítica, excêntrica, com estreita zona de transição com o osso normal, sem esclerose periférica. Este aspecto é observado em até $85 \%$ dos $\operatorname{casos}^{(4)}$. As lesões grandes, entretanto, parecem ter localização central. Reação periosteal é caracterizada, radiograficamente, em menos de um terço dos casos. Em cerca da metade dos pacientes existe um aspecto multiloculado secundário a trabeculação proeminente (na verdade, pseudotrabeculação por sulcos ósseos criados por erosão do endósteo) ${ }^{(\mathbf{6})}$. Raramente, o tumor produz calcificações, sugerindo o diagnóstico de osteossarcoma.

Um sistema de graduação baseado no aspecto radiográfico do TCG foi desenvolvido por Campanacci et al. ${ }^{(7)}$. O tumor grau I apresenta margens bem definidas e um fino halo de osso maduro. O tumor grau II é bem delimitado, porém não apresenta halo esclerótico. A lesão grau III tem bordas mal delimitadas, sugerindo agressividade. Entretanto, esta classificação não parece ter correlação clínica.

Outros métodos de diagnóstico por imagem têm papel importante na caracterização da lesão. A cintilografia óssea demonstra ampla concentração do radioindicador na lesão (Figura 9) e em até 57\% dos casos está presente o "sinal da rosquinha", em que há fotopenia central ${ }^{(\mathbf{6})}$.

A tomografia computadorizada no diagnóstico das lesões ósseas solitárias é tipicamente utilizada por delinear de forma muito superior as alterações da cortical ${ }^{(\mathbf{8})}$. Nos TCG, a tomografia (Figura 10) demonstra mais claramente a expansão ou erosão da cortical, pseudotrabeculações, ausência de matriz mineralizante e eventuais fraturas patológicas ${ }^{(9)}$.

A ressonância magnética é considerada o método de maior importância para avaliar a extensão de tumores ósseos, entretanto, é menos específica no diagnóstico diferencial ${ }^{(\mathbf{1 0})}$. Em imagens de ressonância magnética, o TCG se apresenta mais comumente como lesão bem delimitada, que 


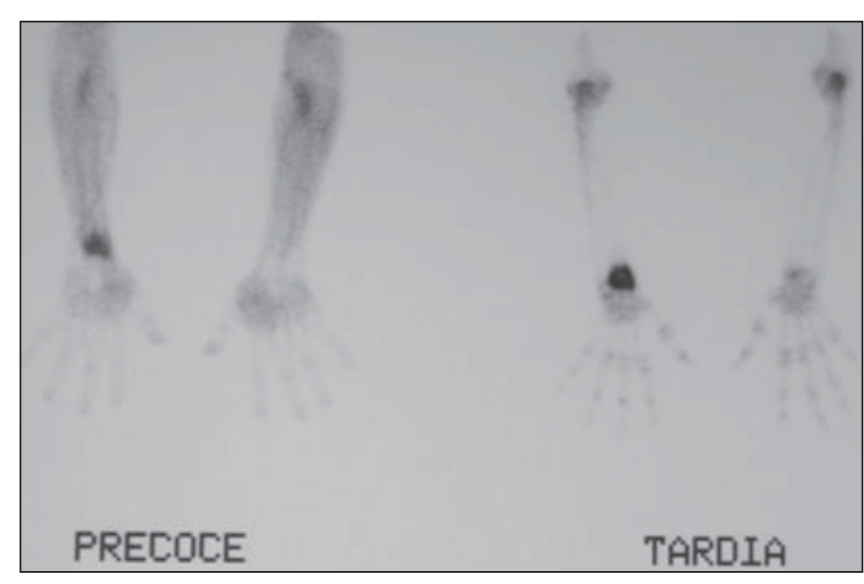

Figura 8. Cintilografia óssea demonstrando hiperconcentração do radioindicador no rádio distal por TCG.

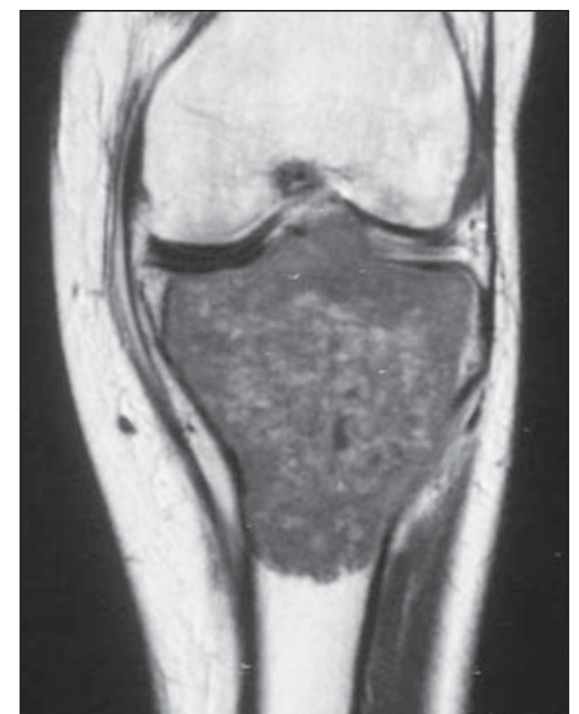

Figura 10. Ressonância magnética de TCG da tíbia proximal ponderada em T1 mostra lesão expansiva com hipossinal e focos de sinal elevado de permeio.

pode ser circundada por halo de baixa intensidade de sinal, representando tanto esclerose reacional como cápsula fibro$\mathrm{sa}^{(6)}$. A maioria das lesões apresenta hipointensidade de sinal em imagens ponderadas tanto em T1 (Figura 10) quanto em T2, fato atribuído à presença de depósitos de hemossiderina e/ou ao alto conteúdo de colágeno $^{(6,9)}$. Este achado pode ser útil para exclusão de outras lesões de localização epifisária, como cistos subcondrais, condroblastoma e condrossarcoma de células claras ${ }^{(6,11)}$. Áreas císticas no interior da lesão também são freqüentemente caracterizadas pela ressonância magnética,

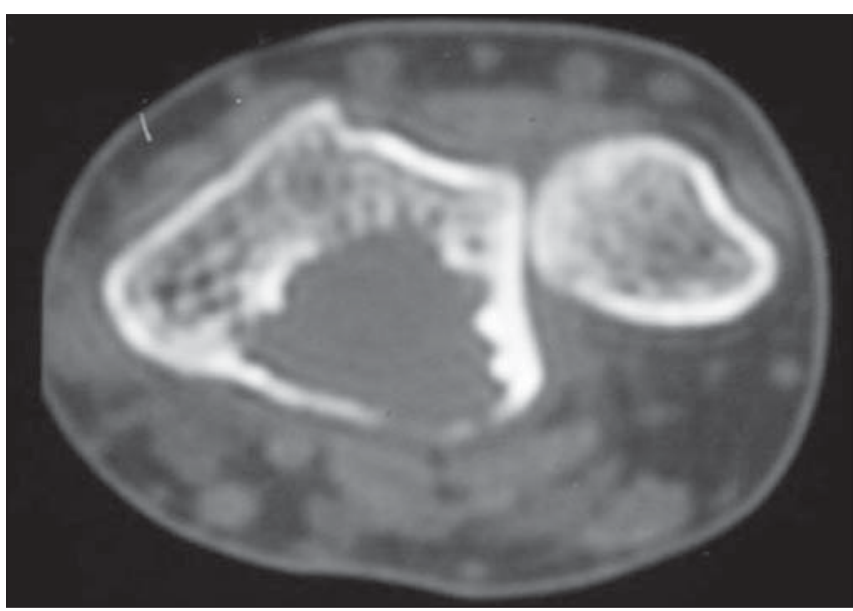

Figura 9. Tomografia computadorizada demonstrando lesão expansiva com densidade de partes moles e erosão da cortical no rádio distal (mesmo caso da Figura 8). podendo ser conseqüentes a hemorragias ou à formação de cistos ósseos aneurismáticos secundários ${ }^{(6,9)}$

Um sistema de graduação cirúrgica similar ao de Campanacci et al. ${ }^{(7)}$ foi desenvolvido por Enneking, também representado por três diferentes graus ${ }^{(\mathbf{1 2})}$. O tratamento padrão varia da curetagem simples até a ressecção ampla e os resultados variam com diferentes trabalhos. A curetagem da lesão, combinada com cauterização das margens e/ou uso de nitrogênio líquido, tem-se mostrado método confiável de tratamento, porém lesões grandes requerem ressecção ampla e reconstrução com prótese ou tecido ósseo autólogo ${ }^{(13)}$.

Recorrência local do TCG é frequientemente observada, mais amiúde nos três primeiros anos após o tratamento. Grandes séries de pacientes com avaliações após o tratamento, como a reportada por O'Donnel et al., demonstram índices de até $25 \%$ de recidiva local ${ }^{(\mathbf{1 4})}$.

\section{CONCLUSÕES}

O tumor de células gigantes é uma neoplasia óssea relativamente comum, com características radiológicas bem definidas. Os aspectos epidemiológicos e radiológicos mais comuns descritos na literatura assemelham-se aos observados em nossa casuística.

\section{REFERÊNCIAS}

1. Goldring SR, Roelke MS, Petrison KK, Bhan AK. Human giant cell tumors of bone identification and characterization of cell types. J Clin Invest 1987; 79:483-491.

2. Grote HJ, Braun M, Kalinski T, et al. Spontaneous malignant transformation of conventional giant cell tumor. Skeletal Radiol 2004;33:169-175.

3. Unni KK. Giant cell tumor. In: Unni KK, editor Dahlin's bone tumors: general aspects and data on 11,087 cases. 5th ed. Philadelphia, Pa: Lippincott Williams \& Wilkins, 1996;263-283.

4. Mirra JM. Bone tumors: diagnosis and treatment. 2nd ed. Philadelphia, Pa: JB Lippincott, 1980:332356.

5. Levine SM, Lambiase RE, Petchprapa CN. Cortical lesions of the tibia: characteristic appearances at conventional radiography. RadioGraphics 2003; 23:157-177.

6. Murphey MD, Nomikos GC, Fleming DJ, et al. Imaging of giant cell tumor and giant cell reparative granuloma of bone: radiologic-pathologic correlation. RadioGraphics 2001;21:1283-1309.

7. Campanacci M, Giunti A, Olmi R. Giant cell tumors of bone: a study of 209 cases with long-term follow-up in 130. Ital J Orthop Traumatol 1975;1: 249-277.

8. Resnick D. Tumors and tumor-like lesions of bone: radiographic principles. In: Resnik D, editor. Diagnosis of bone and joint disorders. Philadelphia, Pa: Saunders, 1995;3613-3627.

9. Woertler K. Benign bone tumors and tumor-like lesions: value of cross-sectional imaging. Eur Radiol 2003;13:1820-1835.

10. Berquist TH. Magnetic resonance imaging of primary skeletal neoplasms. Radiol Clin North Am 1993;31:411-424.

11. Aoki J, Tanikawa $\mathrm{H}$, Ishii $\mathrm{K}$, et al. MR findings indicative of hemosiderin in giant cell tumor of bone: frequency, cause, and diagnostic significance. AJR 1996;166:145-148.

12. Oda Y, Miura H, Tsuneyoshi M, Iwamoto Y. Giant cell tumor of bone: oncological and functional results of long-term follow-up. Jpn J Clin Oncol 1998;28:323-328.

13. Su YP, Chen WM, Chen TH. Giant cell tumors of bone: an analysis of 87 cases. Int Orthop 2004;28: 239-243.

14. Manaster BJ, Doyle AJ. Giant cell tumors of bone. Radiol Clin North Am 1993:31:299-323. 